\title{
Study on the correlation links between parameters of weather conditions and indicators of seed productivity of plants of spring wheat (Tr. aestivum $\mathbf{L}$.) in Irkutsk region
}

\author{
Gennady Ordenovich Takalandze* \\ Irkutsk State Academy of Agriculture, Russia \\ *Correspondent: rector@igsha.ru
}

\begin{abstract}
In Irkutsk region the plants of spring wheat(Tr. aestivum) grow in three agro-ecological zones: steppe, foreststeppe and subtaiga. Due to this reason, the paper determines the coefficients of correlation between the indicators field germination of seeds, plant safety, productivity, temperature and moisture content of the plant habitat for each zone. The zonal moisture saving features of soil treatment for growing wheat plants (Tr. aestivum) are discussed on the basis of these data.
\end{abstract}

Keywords: field germination, plant preservation, plant productivity, spring wheat

\section{INTRODUCTION}

In genetic terms, the species of soft wheat(Tr. aestivum) is hexaploid. It means that in its genome there are three subgenoma (ABD) at the same time. Durum wheat (Tr. durum $\mathrm{L}$.) has only two subgenoma (AB), i.e. it is a tetraploid. The evolutionary complexity of the genome of soft wheat (Tr. aestivum) in comparison with the durum wheat (Tr. durum) allowed greatly expanding the genetic potential of plant adaptation to the ambient diversity and, consequently, the varieties of soft wheat are currently cultivated all over the world, including the regions of Siberia (Tsvelev, 2005).

Grain of soft wheat plants is not only of the highest nutritional qualities (Sandukhadze et al., 2006), but also there is no other cereals of a like nature in the diversity of its use in the food industry (Neudachin et al., 2001). Due to these reasons, soft wheat compared to other cereals has the biggest area in crops of the world and in Russia (Zhuchenko, 2006). In Irkutsk region it occupies 40-60\% of the total sowing area of grain crops (Polnomochnov et al., 2008).

Meanwhile, adaptation potential of wheat plants has its defined boundaries of limits to the conditions of temperature, value of moisture, soil types and fertility.

Therefore, not all the territories of Irkutsk region is suitable for successful crop activities. In particular, the total land area is of approximately 767.90 hectares.

The northern part of the territory is located in the Arctic tundra and taiga. According to the agro-climatic re- sources, it is not suitable for successful crop activities and it takes about 60\% throughout the region (Shotsky, 1956; Gontar et al., 1981).

The southern part is located in the area with relatively favorable climatic conditions for the agricultural development (Gontar et al., 1981). It takes $40 \%$ of the entire territory of Irkutsk region (Fig. 1).

According to agro-climatic characteristics, rural territories are divided into three zones: subtaiga, forest-steppe and steppe. Each of these zones is different in value of temperature, moisture, soil types and its fertility.

It is known (Lykova, 2009) that these factors greatly affect not only the amount of marketable grain of wheat, but also the quality of sowing seeds, which are to realize the genetic potential of varieties productivity (Roach and Wulff, 1978). All these factors need to be adjusted in the agricultural technology for cultivation of plants, i.e. in the system of agriculture. These agro-environmental indicators as a ratio of value of the environmental temperature and moisture of plants in nature are closely related. However, the proportion of the contribution of each indicator into the growth and development of plants to particular crop may be different. It is necessary to know the value of the activity shares of each of the discussed factors in the processes of plant growth and productivity in order to develop the best system of agriculture. In order to determine the proportion of the contribution of heat and moisture provision of plant, it is most advisable to calculate the correlation between weather parameters and indicators of seed production of wheat, which will develop a system of technologies for cultivation of this crop in 


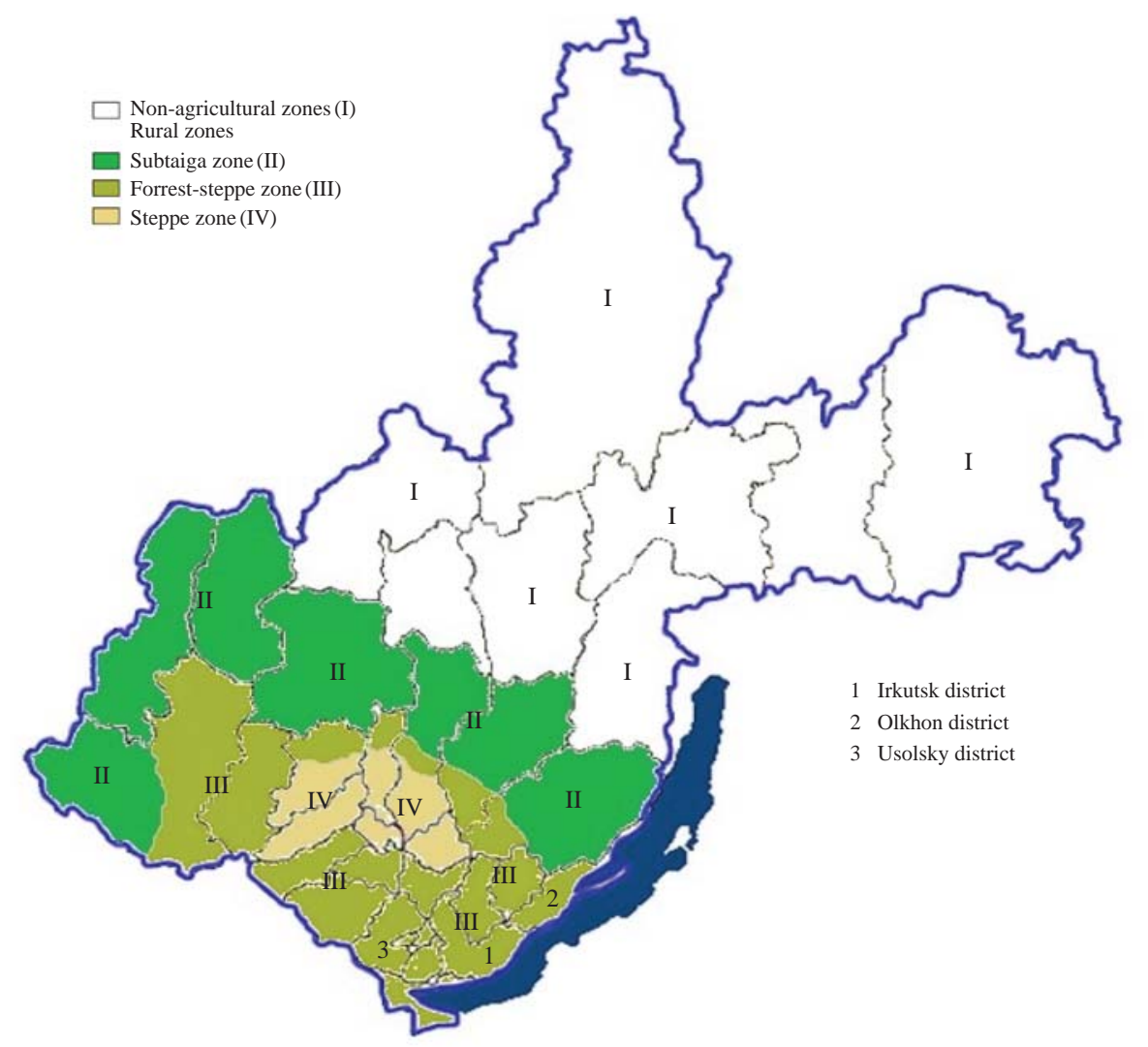

Fig. 1. Rural territories of Irkutsk region.

each of these areas of Irkutsk region.

\section{Materials And Methods}

The objects of the given research were the plants of spring wheat grown on variety testing plots of Irkutsk region for 11 years (1996-2006). The indicators of field germination rates of plants, plant preservation to the period of harvesting and seed productivity of plants (yield) were used for the calculation of the correlation links. The data on temperature and moisture supply regime of plants for 11 years (1996-2006) were provided by Irkutsk Regional Agrometeoservice.

The correlation coefficient was calculated using the following formula (Rumshisky, 1971):

$$
r=\frac{1}{S_{x} S_{y}} \times \frac{1}{n-1} \sum_{i=1}^{n}\left(x_{i}-\bar{x}\right)\left(y_{i}-\bar{y}\right), \text { where }
$$

$\mathrm{x}$-biological value of indicator of plant growth and development;

$\mathrm{y}$-value of indicator of plant temperature and moisture supply;

n-number of measurements.

\section{Discussion}

The performed calculations of the correlation between field germination temperature and the sum of temperatures equal to $10^{\circ} \mathrm{C}$ and above during the period from May to the first part of June in the forest-steppe zone showed (Table 1) that this link is positive. The correlation coefficient constituted 0.508 . In the steppe zone this dependence was less expressed and the ratio was equal to 0.405 units, whereas in the subtaiga-taiga zone the correlation coefficient increased to 0.608 .

The similar correlation was observed between the field germination and the average daily air temperature for the period from May to the first part of June. The only difference was that the indicators of the correlation coefficient in the forest-steppe and subtaiga-taiga zones were significantly lower than in the steppe zone. Thus, in Irkutsk region the temperature factor has a significant impact on the process of seed germination and seedling emergence of good spring wheat. On this stage of the plant development the heat deficit was the largest one in the subtaiga-taiga zone. Hence the indicator of the correlation coefficient was highest. In the case of the indicator of 
Table 1. Coefficient of correlation between field germination of seeds of spring wheat and weather conditions for the period of 11 years in Irkutsk region.

\begin{tabular}{lccr}
\hline Indicators of meteorological conditions for the period of & \multicolumn{2}{c}{ Zone } \\
\cline { 2 - 4 }$\quad$ May and the first part of June & Steppe & Forest-steppe (control) & Subtaiga-taiga \\
\hline Average daily air temperature, ${ }^{\circ} \mathrm{C}$ & 0.285 & 0.517 & 0.560 \\
Sum of the active temperatures equal to $10^{\circ} \mathrm{C}$ and above & 0.405 & 0.508 & 0.608 \\
Sum of precipitation, $\mathrm{mm}$ & 0.605 & 0.319 & 0.166 \\
\hline
\end{tabular}

Table 2. Coefficient of correlations between preservation of plants of spring wheat before harvesting and weather conditions of the Baikal area.

\begin{tabular}{|c|c|c|c|}
\hline \multirow[b]{2}{*}{ Indicator } & \multicolumn{3}{|c|}{ Zone } \\
\hline & Steppe & $\begin{array}{l}\text { Forest-steppe } \\
\quad(\text { control })\end{array}$ & Subtaiga-taiga \\
\hline Average daily air temperature for the whole vegetation period of spring wheat, ${ }^{\circ} \mathrm{C}$ & 0.372 & 0.575 & 0.802 \\
\hline $\begin{array}{l}\text { Sum of the active temperatures equal to } 10^{\circ} \mathrm{C} \text { and above for the whole } \\
\text { vegetation period of spring wheat }\end{array}$ & 0.232 & 0.569 & 0.824 \\
\hline $\begin{array}{l}\text { Sum of the active temperatures equal to } 15^{\circ} \mathrm{C} \text { and above for the whole vegetation } \\
\text { period of spring wheat }\end{array}$ & 0.193 & 0.867 & 0.880 \\
\hline Sum of precipitation for the whole vegetation period of spring wheat, $\mathrm{mm}$ & 0.633 & 0.632 & 0.018 \\
\hline
\end{tabular}

the sum of the active temperatures, the correlation coefficient constituted 0.608 . It means that the process of seed germination under the field conditions depends on the environment temperature by $60 \%$ and only by $17 \%$ it depends on the lack of moisture in the soil.

It would seem that in steppe zone which is more warm, but has fewer amounts of precipitations, these figures should be opposite. They are really opposite only in the tendency, but in absolute indicators of correlation links they are not identical. In particular, in the arid steppe zone the field germination of seeds depends on soil moisture by $60 \%$. However, under the same conditions, the process of seed germination depends on the environment temperature by $40 \%$. It means that in steppe zone, which is provided with the warmth better than other areas, this factor is deficit for plant wheat, and the plants begin to experience this lack factor at the very early stages of ontogeny.

Along with field germination, the important component in the structure of the harvest of spring wheat is the number of surviving plants before harvesting.

The indicator of correlation links between plant preservation before the harvest and the amount of temperature equal to $10^{\circ} \mathrm{C}$ and above during the entire vegetation season in the particular forest-steppe zone (Table 2) was highest and constituted 0.569 . In the subtaiga-taiga zone it was by 1.5-2.0 times lower and constituted 0.232 and 0.324 , respectively. It is well known (Mashkevich, 1974) that more than $95 \%$ of all the dead plants before harvest are registered for the ontogeny period of spring wheat and the flowering phase. In this regard, the search for correlation links between the plant preservation and hydrothermal indicators during the formation of grains has no logical sense. However, these indicators have a significant impact on the productivity of plants.

In the case, when we determined the correlation between the average daily air temperature and plant preservation, there had been determined the distinct link between the heat supply of the zone and the preservation of plants (Table 2). In the warmest steppe zone this link was the lowest one, and constituted 0.372 , but in the coolest subtaiga-taiga zone it was the highest one and reached 0.802 .

The analysis of the correlation link between the sum of temperatures equal to $10^{\circ} \mathrm{C}$ as well as $15^{\circ} \mathrm{C}$ and above and plant preservation before harvesting has shown the same, but more expressed dependence.

The correlation coefficient between the preservation of plants and moisture supply of the ecological zones showed that it was high in the areas of poor moisture. In particular, in the steppe and forest steppe zones it constituted 0.633 and 0.632 , respectively. In the area of favorable conditions (subtaiga-taiga), this indicator of the link was not practically observed, since it was equal to 0.018 .

In conclusion, it should be noted that the indicator of the preservation of plants was undoubtedly influenced by the value of the air temperature during the vegetation season of plants and amount of precipitation during the same period. Based on these data, it can be stated that in the steppe and forest-steppe zones the summer loss of plants is mainly due to moisture lack, and in the subtaigataiga zone this negative process is conditioned by heat lack.

The analysis of the dynamics of winter wheat yield on the three agricultural zones of the region (Table 3 ) for the period from 1996 to 2006 has shown that in some years it ranged from $0.6 \mathrm{t} / \mathrm{ha}$ (steppe zone) to $4.9 \mathrm{t} / \mathrm{ha}$ (subtaiga- 
Table 3. Coefficient of correlation between yield of spring wheat and weather conditions for 11 years in the zones of the region.

\begin{tabular}{|c|c|c|c|}
\hline \multirow[b]{2}{*}{ Indicator } & \multicolumn{3}{|c|}{ Zone } \\
\hline & Steppe & $\begin{array}{l}\text { Forest-steppe } \\
\quad(\text { control })\end{array}$ & Subtaiga-taiga \\
\hline $\begin{array}{l}\text { Sum of the active temperatures equal to } 10^{\circ} \mathrm{C} \text { and above for the whole } \\
\text { vegetation period of spring wheat }\end{array}$ & 0.397 & 0.549 & 0.624 \\
\hline $\begin{array}{l}\text { Sum of the active temperatures equal to } 10^{\circ} \mathrm{C} \text { and above for the period of } \\
\text { wheat grain formation }\end{array}$ & 0.508 & 0.638 & 0.661 \\
\hline $\begin{array}{l}\text { Sum of the active temperatures equal to } 15^{\circ} \mathrm{C} \text { and above for the whole } \\
\text { vegetation period of spring wheat }\end{array}$ & 0.548 & 0.713 & 0.777 \\
\hline $\begin{array}{l}\text { Sum of the active temperatures equal to } 15^{\circ} \mathrm{C} \text { and above for the period of } \\
\text { wheat grain formation }\end{array}$ & 0.699 & 0.787 & 0.802 \\
\hline Average daily air temperature for the above vegetation period of spring wheat, ${ }^{\circ} \mathrm{C}$ & -0.264 & 0.545 & 0.414 \\
\hline Average daily air temperature for the period of wheat grain formation, ${ }^{\circ} \mathrm{C}$ & 0.092 & 0.536 & 0.626 \\
\hline Sum of precipitation for the whole vegetation period of spring wheat, $\mathrm{mm}$ & 0.743 & 0.627 & 0.504 \\
\hline Sum of precipitation for the period of wheat grain formation, $\mathrm{mm}$ & 0.799 & 0.668 & 0.604 \\
\hline
\end{tabular}

taiga) in the zones. Following the recommended technology of spring wheat cultivation on the variety testing plots in steams there is rather great difference in yields. The average yields in the forest-steppe zone of Irkutsk region constituted of $2.7 \mathrm{t} / \mathrm{ha}$ on average over 11 years. Since this area has the majority of the arable land of Irkutsk region, the yield value of this area was taken as a control option. In the steppe zone the average yield was of $1.1 \mathrm{t} / \mathrm{ha}$. Compared with the forest-steppe zone it was only $39.7 \%$. In the subtaiga-taiga area the average yield was $3.1 \mathrm{t} / \mathrm{ha}$. It was by 3 times higher than in steppe zone and $15.2 \%$ higher than in the control forest-steppe zone.

The analysis of the indicators of correlation links (Table 3) has shown that the yield of spring wheat plants in Irkutsk region largely depends on the sum of active temperatures during the vegetation season. It turned out that the cooler area (the sum of temperatures equal to $10^{\circ} \mathrm{C}$ and above) means the higher dependence. The correlation coefficient for steppe, forest-steppe and subtaiga-taiga zones constituted $0.397,0.549$ and 0.624 , respectively.

When the temperature indicator was taken as the time interval falling on the period of grain formation, the dependence of the yield of plants was higher, consequently, higher the above named sequence of the zones, the correlation coefficient constituted $0.508,0.638$ and 0.661 . In the case, when we presented high requirements for the criterion of the temperature, that is we have chosen the sum of the temperatures at which during the entire vegetation period the average air temperature did not drop below $15^{\circ} \mathrm{C}$, the dependence of plant productivity on the temperature constituted $0.548,0.713$ and 0.777 , respectively. Finally, when we determined the dependence on plant productivity by the sum of the air temperatures of $15^{\circ} \mathrm{C}$ and above during the formation of seeds, it turned out to be highest and constituted $0.699,0.787$ and 0.802 , respectively.

Thus, we found out that in Irkutsk region the plants of spring wheat are not provided with sufficient amount of heat in any agricultural zones. Hence it clearly follows that it is necessary to use a set of varieties adapted to local conditions of temperature along with the zone technology of wheat cultivation in Irkutsk region.

The data analysis of correlation links also has shown that Siberian varieties in Irkutsk region are unstable not only to low positive temperature, but also to spring-summer drought. This negative effect can be significantly reduced by the introduction of flat hoe subsurface tillage in Irkutsk region (Takalandze, 1991; 1993). Meanwhile, flat hoe subsurface tillage should be used only in steppe zone to improve water supply of plants. This method is impractical in subtaiga zone, because the observable short vegetation season can lead to unwanted plants of wild species. In the forest-steppe zone the flat hoe subsurface tillage should be alternated with conventional moldboard treatment, which will also reduce the weed damage rate of wheat plantings.

\section{REFERENCES}

Gontar, V.I., S.I. Eremin and L.M. Makarova. 1981. Agricultural system of Irkutsk region, Irkutsk. pp. 9-22 (in Russian).

Lykova, N.A. 2009. Effect of pre-vegetation: ecological aftereffects. Science, Saint-Petersburg. pp. 1-311 (in Russian).

Mashkevich, N.I. 1974. Crop production. Higher school, Moscow. pp. 1-455 (in Russian).

Neudachin, V.P., V.G. Zima and G.I. Bukreeva. 2001. Link of gliadin components with the quality of gluten of winter wheat in Krasnodar area, Krasnodar. pp. 367-374 (in Russian).

Polnomochnov, A.V., I.E. Illi and I.A. Krutikov. 2008. Spring wheat of Cisbaikalia and results of agricultural crop zoning. House of Publication, Irkutsk. pp. 1-288 (in Russian). 
Roach, D.A. and R.D. Wulff. 1987. Maternal effects in plants. Ann. Rev. Ecol. Syst. 18:239-251.

Rumshisky, L.Z. 1971. Mathematical proceeding of experiment results. Science, Moscow. pp. 1-192 (in Russian).

Sandukhadze, B.I., B.P. Loboda, D.F. Askhadullin and E.V. Zhuravleva. 2006. Influence of nitrogen application on nitrogen content in soil and plants of winter wheat. Agrochem, vestnik. 11:10-12 (in Russian).

Shotsky, V.P. 1956. Nature conditions of agricultural production and natural historical areas of Irkutsk region. Eastern Siberian Book House, Irkutsk. pp. 1-126 (in Russian).

Takalandze, G.O. and A.G. Belykh. 1991. Technologies of differential treatment of early steam for the conditions of the East Siberia. CSTI, Irkutsk. pp. 1-4 (in Russian).
Takalandze, G.O. 1993. Rationale for minimal treatment of the leached chernozem in the field rotation of the foreststeppe zone of the Angara area. Dissertation abstract of candidate of agricultural sciences, Irkutsk. pp. 1-19 (in Russian).

Tsvelev, N.N. 2005.On origin and main directions of evolution of cereals (Poaceae). Scientific Book House, SaintPetersburg. pp. 280-292 (in Russian).

Zhuchenko, A.A. 2006. Role of plant breeding in the century of knowledge of biology and economics, Vestnik RAAS 1:3-6 (in Russian).

Submitted: June 28, 2012, Accepted: August 24, 2012 